\title{
Energy Audits and Energy Efficiency in Small Wastewater Treatment Plants: A Case Study
}

\author{
Bruno J. Cardoso ${ }^{1,2,3 *[0000-0003-4298-2789]}$, Adélio R. Gaspar ${ }^{10000-0001-6947-4579]}$ and Álvaro \\ Gomes 4 [0000-0003-1229-6243] \\ ${ }^{1}$ ADAI, LAETA \& Dept. of Mechanical Engineering, Faculty of Sciences and Technology, \\ University of Coimbra, Rua Luís Reis Santos, Pólo II, 3030-788 Coimbra, Portugal \\ bruno.cardoso@adai.pt (*corresponding author); adelio.gaspar@dem.uc.pt \\ 2 Águas do Norte, S.A., Rua Dom Pedro de Castro, n. ${ }^{\circ}$ 1A, 5000-669 Vila Real, Portugal \\ bruno.cardoso@adp.pt \\ ${ }^{3}$ DTe, Lda., Rua Serpa Pinto ed. Fajal 1. ${ }^{\circ}$ Dto, 5050-284 Peso da Régua, Portugal \\ dtempresas@gmail.com \\ ${ }^{4}$ INESC Coimbra \& Department of Electrical and Computer Engineering, Faculty of Sciences \\ and Technology, University of Coimbra, Rua Luís Reis Santos, Pólo II, 3030-788 Coimbra, \\ Portugal \\ agomes@deec.uc.pt
}

\begin{abstract}
Energy plays an important role in the water sector. In fact, energy consumption by this sector accounts for nearly $44 \%$ of municipalities' energy costs in developed countries.

To minimize adverse environmental and human health impacts wastewater can undergo three treatment levels before discharge or reuse. Since it is an energy intensive process, wastewater treatment represents the largest share of water-related electricity consumption in developed countries.

According to the literature, there is a potential for improvement and energy savings in wastewater treatment facilities. Indeed, International Energy Agency states that, the energy consumption in the water sector can be reduced by $15 \%$ if this potential is harnessed. Consequently, energy audits can provide valuable information about those facilities, allowing to assess their energy performance and to identify energy-saving opportunities.

In this paper the results of internal energy audits conducted in two "small" wastewater treatment plants, located in the North of Portugal, are presented and analyzed. The results, $13 \%$ and $22 \%$ savings, show that simple energy audits, which can be implemented by company members, should not be considered as a cost, but rather as a step to a more efficient energy use, reducing energy costs and environmental impacts.
\end{abstract}

Keywords: Energy Efficiency, Wastewater Treatment Plants, Energy Audits, Sustainability. 


\section{Introduction}

The water sector is remarkably dependent on energy and the main contributor to municipal energy use in developed countries, since water utilities account for nearly $44 \%$ of municipalities' energy costs [1, 2]. Overall, the energy demand of this sector in 2014 was 120 Mtoe, being predominantly in the form of electricity $(60 \%)$, which represents $4 \%(820 \mathrm{TWh})$ of the total global electricity consumption [3]. Wastewater treatment exploits the largest share of water-related electricity consumption in developed countries (42\%), while in developing and emerging countries it represents a smaller share, since a smaller portion of wastewater is currently collected and treated to a lesser degree [3].

Wastewater treatment plants (WWTPs) are essential to minimize adverse environmental and human health impacts, as they ensure the quality of the treated water prior to discharge or reuse, by submitting wastewater to appropriate treatment. Depending on several factors, such as contamination level, population served or discharge standards, wastewater can undergo up to three treatment stages - primary, secondary and tertiary [3, 4]. Given the diversity and complexity of processes, WWTPs depend heavily on energy and are considered as energy-intensive facilities [5, 6]. In fact, energy represents the second largest portion of the operating costs of these facilities, only being exceeded by personnel costs [1].

The number of people gaining access to improved sanitation facilities are expected to maintain the growth observed during the last decades, thus continuing to increase the number of WWTPs operating worldwide [7]. This trend, coupled with the increasingly stringent effluent quality, should turn this sector even more energy intensive [5]. Therefore, the energy performance of WWTPs becomes a fundamental matter in order to maintain the sustainability of this sector, while maintaining the quality of service, guaranteeing the environmental management of the water resources and reducing operating costs $[7,8]$.

Literature claims that wastewater facilities have much room for improvement and that noteworthy reductions in energy consumption could be achieved. In fact, International Energy Agency predicts that, if the economically available energy efficiency and recovery potentials are exploited, the energy consumption in the water sector can be reduced by $15 \%$ in 2040 [3]. Consequently, it is essential to identify the main uses of energy in WWTPs and to develop strategies to increase energy efficiency of these facilities [9]. Energy audits can be important in promoting and disseminating energy efficiency as they can help attain the above objectives [10]. Additionally, it allows the analysis of energy flows of the process as well as the identification of measures to reduce not only energy consumption but also carbon footprint [11].

In this context, this paper presents the results of internal energy audits conducted to two "small" WWTPs, located in the North of Portugal, with 21000 and 19300 population equivalent, respectively. This analysis examines which are the most important end uses of these facilities and identifies some auspicious energy-saving measures that allow significant savings without the need for large investments.

The paper develops as follows. In section 2, the treatment process of the two WWTPs is characterized and the methodology used in the energy audits is presented. In turn, in 
section 3, the results obtained from this study are presented and analyzed, i.e., the end uses with the greatest impact on the energy consumption of the WWTPs are identified, as well as the energy-saving measures that should be implemented to reduce that consumption.

\section{Framework and Methodology}

The two facilities considered in this analysis treat wastewater from two small municipalities located in the North of Portugal and are designed to treat influent from a population equivalent of 21000 and 19300 , although they currently receive a smaller amount of wastewater. In fact, from the average daily flow it is possible to estimate that the real population equivalent of the two facilities are 12874 and 15082, respectively. Both WWTPs are activated sludge plants, i.e., the process is composed by a biological reactor, a secondary clarifier and a returning mechanism, typically a pumping system, to recirculate a portion of the settled sludge from the clarifier to the biological reactor. As far as biological reactors are concerned, WWTP1 is composed by an oxidation ditch while WWTP2 has an aeration tank. It should also be noted that at the beginning of the biological reactor of each WWTP there is an anoxic tank, and that the aeration systems used in the biological reactor are of the diffused type (injecting compress air directly into the bottom of the tank through diffusers). Additionally, both facilities apply a tertiary treatment in their process, namely the removal of nutrients (nitrogen and/or phosphorous) and the disinfection through ultraviolet light (UV).

Before safe disposal, the sludge accumulated in the wastewater treatment process in the WWTPs is subject to adequate treatment in the solid phase, namely thickening, anaerobic digestion and dewatering. It should be noted that these facilities receive sludge from other facilities which, due to their smaller size, are not capable of treating the sludge generated. Finally, in both WWTPs an odor control is applied to treat the gases generated during some stages of the process, being hydrogen sulfide one of the most common. This treatment intends to safeguard workers' health, reduce odors for the population and protect equipment and structures.

Table 1 presents some characteristics of the two WWTPs analyzed during the energy audits. As shown, the two facilities have similarities in the volume of wastewater treated annually. However, despite this similarity, there are clear differences in some values, especially in terms of solids, organic load and nutrients removed, as well as of annual energy consumption. In fact, the energy intensity of WWTP2 $\left(1.17 \mathrm{kWh} / \mathrm{m}^{3}\right)$ is clearly higher than that of WWTP $1\left(1.08 \mathrm{kWh} / \mathrm{m}^{3}\right)$, while the quantities of substances (solids, organic load and nutrients) removed are unmistakably lower.

Table 1. - Characteristics of the two WWTPs in the sample.

\begin{tabular}{ccc} 
& WWTP1 & WWTP2 \\
\cline { 2 - 3 } Start of operation & 2005 & 2004 \\
Design capacity (population equivalent) & 21000 & 19300 \\
Annual volume of wastewater treated $\left(\mathrm{m}^{3}\right)$ & 609090 & 643868 \\
Annual energy consumption $(\mathrm{kWh} / \mathrm{toe})$ & $657494 / 141$ & $753705 / 162$ \\
\hline
\end{tabular}




\begin{tabular}{ccc}
\hline Total annual suspended solids removed $(\mathrm{kg})$ & 179157 & 150214 \\
Annual chemical oxygen demand removed $(\mathrm{kg})$ & 507002 & 350264 \\
Total annual phosphorous removed $(\mathrm{kg})$ & 6703 & 4314 \\
Total annual nitrogen removed $(\mathrm{kg})$ & 51188 & 41208 \\
\hline
\end{tabular}

As portrayed in Table 1, the energy consumption of the two facilities - 141 and 162 tones of oil equivalent (toe), respectively- is significantly lower than the threshold (500 toe) established by the Management System of Intensive Energy Consumption (SGCIE) for the legal obligation to conduct energy audits on a regular basis and implement consequent rationalization plans [12]. Since there is no obligation, occasionally their energy consumption tends to be neglected and these facilities do not benefit from the implementation of resulting measures, nor the assessment of their energy breakdown. This often results in misuses and energy waste as common practices, as well as in the existence of energy-saving opportunities which, if adopted, could lead to a reduction in their energy consumption, thus increasing their efficiency and reducing costs.

Moreover, as suggested in the literature, smaller WWTPs could improve their environmental profile if they benefited from stricter supervision just as large WWTPs do [13], showing the importance of energy audits in energy management efforts, as it helps facilities to target the most inefficient aspects of their operations [10].

The conducted energy audits were divided into two phases. In the preliminary phase, a walk-through on the facility was performed to get acquainted with the treatment process (liquid, solid and gaseous line), enabling the identification of potential energy misuses and the selection of end uses to be monitored in the detailed phase. In addition, data displayed in Table 1 was collected during this phase to understand some features of the two facilities. In the second phase a more thorough analysis is carried out, often involving equipment field tests, discussing potential energy conservation measures and their payback periods, as well as creating energy profiles for systems and equipment [10]. Therefore, during this phase, power analyzers were used to monitor the global energy consumption and some previously identified end uses, such as blowers, submersible mixers and pumps. Subsequently, the data collected during both phases was carefully analyzed. As a result, the most important end uses in both WWTPs were identified, and some energy-saving measures suggested and analyzed.

\section{Results and Discussion}

Fig. 1 shows the load diagram of the two facilities during two day of the monitoring period (lasting a full week -7 days). As depicted, WWTP2 presents a higher average energy consumption during this period, which is in accordance with the annual energy consumption values shown in Table 1 . 


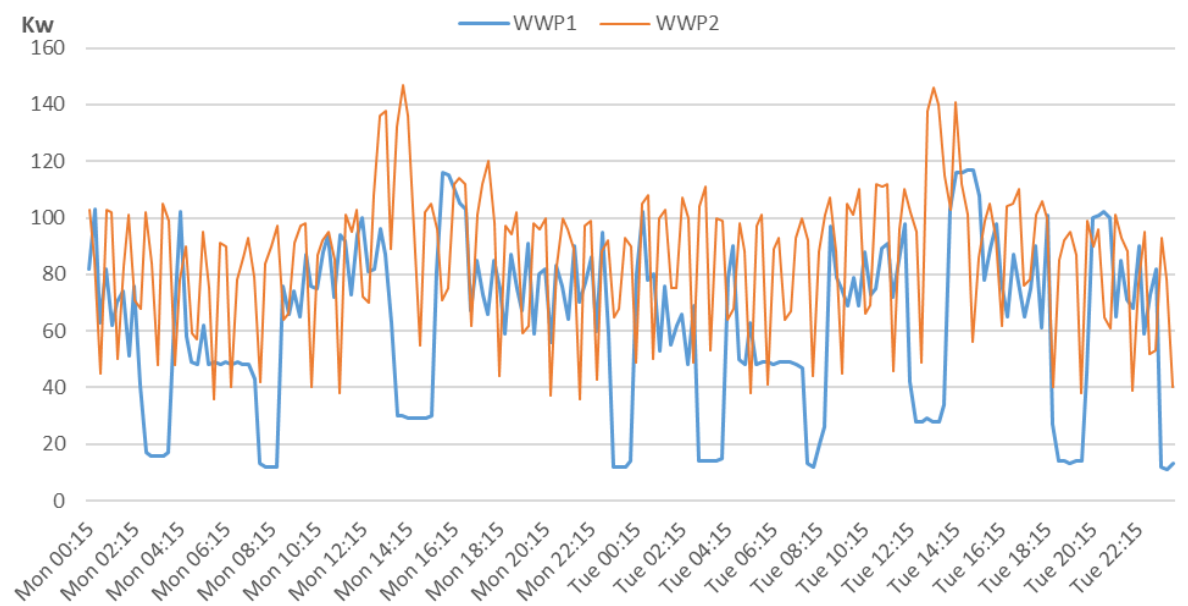

Fig. 1. Load diagram of the two WWTPs during two monitored days.

Aeration plays a significant role in wastewater treatment as it satisfies the oxygen requirements of the biological process. These systems generally have a great power and run almost continuously, accounting for most of the total energy consumption of WWTPs. This significant consumption is due to the importance they have in the treatment process and as such their control should always ensure that the dissolved oxygen in the wastewater is enough so that the microorganisms can use it in the reactions to degrade the organic material. According to literature [14-16], aeration equipment consumes between $40 \%$ and $75 \%$ of the total energy consumption from large to small plants, respectively. This importance is straightforward in these two WWTPs, since aeration systems represent $38.3 \%$ (WWTP1) and $67.7 \%$ (WWTP2) of the total energy consumption (Fig. 2).

Notwithstanding having lower installed power than aeration systems, other equipment, such as submersible mixers and recirculation pumps, also usually work over extended periods of time. Thus, after the aeration systems, these equipment account for most of the energy consumption. In fact, the submersible mixers, existing in the anoxic tanks at the beginning of each biological reactor, represent the second largest share of the energy consumption in each WWTP (10.5\% and $14.8 \%$, respectively).

According to literature $[3,15,17]$, sludge treatment represents an important energy use in WWTPs. The situation is similar in these two facilities since the monitored equipment belonging to this treatment phase (not whole the existing equipment) represents a significant portion of the energy consumption of each WWTP, namely $6.2 \%$ and $18.9 \%$ for WWTP1 and WWTP2, respectively. Moreover, the digesters' agitators of WWTP2 are the third energy consumer at the facility, with nearly $12.6 \%$ of the total.

Finally, it should be noted that the energy consumption of the tertiary treatment (UV system) is not displayed in Fig. 2 since during the monitoring period the system in the WWTP1 was out of order, while in WWTP2 there was no proper conditions to perform the measurement. Furthermore, the component "others" includes all the equipment that has not been monitored, such as lighting, HVAC systems, small motors and pumps, etc. 

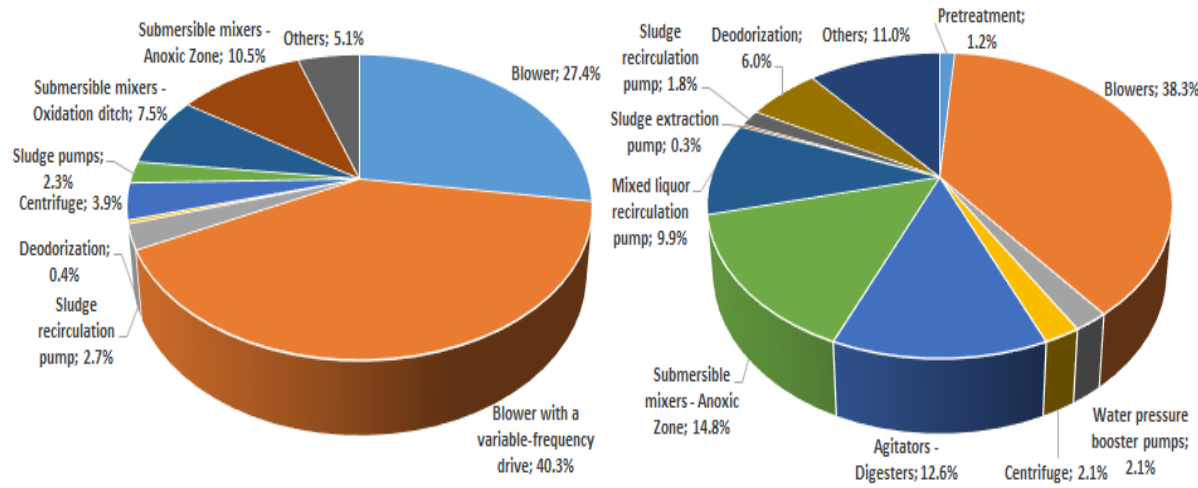

Fig. 2. Total energy consumption by end uses of WWTP1 (left) and of WWTP2 (right)

By identifying the main energy consumers in both facilities, it is possible to define priority targets for analysis, i.e., to identify the end uses in which potential energysaving measures may be found. As such, aeration systems, agitators and submersible mixers (in the anoxic tanks and oxidation ditch) become the main targets in this study. Table 2 presents the energy-saving measures identified during the energy auditing process to both WWTPs.

In the oxidation ditch of the WWTP1 there are some submersible mixers whose main objective is to ensure that the fluid is always in motion, reducing the possibility of sedimentation in the biological reactor. These mixers operate continuously and show remarkable levels of energy consumption (7.5\%). As previously stated, the WWTP is operating below its full capacity, and as such the equipment are also operating below the conditions for which they were dimensioned. Thus, after a joint analysis with the person responsible for coordinating the facility and controlling the treatment process, it was concluded that it was possible to modify the operating profile of these equipment without jeopardizing the process and while obtaining some energy savings. As such, since it is not possible to change the speed of rotation of the equipment -because they are not equipped with variable-frequency drives -, this energy-saving measure suggests the modification of the operating profile to 40 minutes of operation interleaved with a 20 minutes idle period. Nevertheless, this change shall be performed in such a way as to assure that at least one equipment (20 min.; 20min.) and a simultaneous operating period (20 min.) are guaranteed to safeguard the movement of the fluid in the oxidation ditch. With this change, the savings are estimated at around $33 \%$ of the energy consumption of these equipment, which overall would correspond to savings of around $2.5 \%$ of the total energy consumption of WWTP1.

Like the mixers in the oxidation ditch, the submersible mixers in the anoxic tank also operate continuously, which justifies the substantial energy consumption presented, and in different conditions from those to which they were dimensioned (full WWTP's capacity). Thus, in the same way as the first ones, also for these mixers was analyzed, the possibility to change their operation without risking their purpose in the treatment process. As a result, an operating profile like the other mixers (40 min. on; $20 \mathrm{~min}$. off) has been proposed, while always guaranteeing the operation of at least one of the mixers. 
Consequently, such adoption will result in overall savings of nearly 3.5\% (around 33\% in terms of equipment).

At WWTP1 only one of the three existing recirculation pumps currently operates, working almost continuously, i.e. being turned off in two one-hour periods (23:30 00:30 and 07:30 - 08:30) during the day to save energy. However, during the monitoring process it was noticed that one of these periods $(23: 30-00: 30)$ was not the most appropriate since the periods of inactivity should occur when the need for recirculation is lower, as for example when the affluent rate is higher. Hence, it was proposed to change this period (23:30 - 00:30) to another (08:30 - 09:30), as well as to add two new one-hour periods during the day $(19: 30-20: 30 ; 20: 30-21: 30)$. The addition of these two new periods will save $7 \%$ of its energy consumption, despite representing only a saving of $0.2 \%$ in terms of the facility.

As aeration systems are the main energy consumers in both WWTPs, they probably offer the greatest opportunity for energy savings. In fact, literature states that, by optimizing these systems, between 15 and 38\% of energy savings can be attained [16]. The aeration systems used in both facilities inject compressed air through diffusers at the bottom of each biological reactor. Currently, the diffusers applied are of the coarse bubble type, and already have some considerable lifetime. During the walk-through it was reported that the existing diffusers show signs of degradation, and in some cases the disruption of membranes already occurred and was subsequently repaired.

Therefore, it was proposed to replace the existing system with a fine bubble type in both facilities. This is one of the measures usually applied in this type of systems and, according to the literature, can allow energy savings between 10 and 20\% [18]. These estimated savings occur because this substitution leads to an increase in total bubble surface area and to a longer contact time (small bubbles will ascend more slowly through wastewater), thus leading to a greater oxygen transfer and requiring a smaller amount of air and a lower energy consumption. In this case it was considered that the implementation of this measure would save approximately $10 \%$ of the energy consumption of the aeration system in each plant, which would translate into $6.8 \%$ and $3.8 \%$ of the total energy consumption of WWTP1 and WWTP2, respectively. Due to the complexity of this measure, a more thorough analysis was recommended to assess not only the advantages and disadvantages of both systems, but also the changes that should be made to the control system of the treatment process.

Some equipment in both WWTPs are difficult to optimize their operation due to their characteristics or to the lack of appropriate automation. For example, in WWTP1 moving the operation of the equipment from the sludge treatment to the night period is very difficult since starting, stopping and any kind of control of the centrifuge must be done manually and locally. Other example are the UV systems since their operation cannot be moved and occurs during the periods in which the cost of energy is more expensive. As such, it is suggested the installation of photovoltaic panels to meet a portion of the energy demand of some of these equipment in both WWTPs, thus reducing the energy requested to the grid. However, a more thorough analysis should be performed to determine, for example, the required installed capacity, the orientation or the necessity of storage capacity. Given this variety of options available, a more detailed study will be carried out in a future work to evaluate and compare the them, assessing the impact of 
their implementation as well as to determine which is the most suitable for this case. As such, in this work the installation of photovoltaic panels is only suggested, without defining the final choice or determining the amount of purchased energy to be reduced.

In WWTP2, the agitators of the digesters account for nearly $12.6 \%$ of the total energy consumption. During the assessment it was found that they had a continuous operation and that they operated under different conditions for which they were designed (WWTP's full capacity). In view of this, it was concluded that their operation could be altered without impairing their function since there is no need for continuous agitation of the sludge in the digester. As such, an intermittent operation profile (15 min. on; $60 \mathrm{~min}$. off) has been proposed and will result in the savings of roughly $76 \%$ of the energy consumption of the equipment, as well as $11.2 \%$ of the global energy consumption.

In the anoxic tank of the WWTP2 there are two submersible mixers that operate continuously. By analyzing their operation, it was noticeable that, similarly to WWTP1, they work in different conditions from those to which they have been dimensioned and that are not equipped with variable-frequency drives to adapt their operation to the actual needs. Thus, it was suggested a modification without affecting the treatment process, i.e., switch to an intermittent operating profile (15 min. on; $20 \mathrm{~min}$. off) was also proposed. By applying this action, it will be possible to achieve a $55 \%$ reduction in the energy consumption of these equipment, corresponding to an overall saving of almost $7 \%$.

Table 2. Identified energy-saving measures.

\begin{tabular}{|c|c|c|c|}
\hline & \multirow{2}{*}{\multicolumn{3}{|c|}{ Savings }} \\
\hline & & & \\
\hline & $\%$ & kWh & $€$ \\
\hline \multicolumn{4}{|l|}{ WWTP1 } \\
\hline $\begin{array}{l}\text { Change the operating profile of the submersible mixers } \\
\text { (oxidation ditch) }\end{array}$ & 2.5 & 16421 & 1576 \\
\hline $\begin{array}{l}\text { Change the operating profile of the submersible mixers } \\
\text { (anoxic tank) }\end{array}$ & 3.5 & 22989 & 2207 \\
\hline Change the operating profile of the recirculation pumps & 0.2 & 1278 & 123 \\
\hline Replace the existing coarse bubble diffusers & 6.8 & 44509 & 4273 \\
\hline Install photovoltaic panels & \multicolumn{3}{|c|}{ Not determined } \\
\hline \multicolumn{4}{|l|}{ WWTP2 } \\
\hline Change the operating profile of the agitators (digesters) & 7.0 & 53283 & 5081 \\
\hline $\begin{array}{l}\text { Change the operating profile of the submersible mixers } \\
\text { (anoxic tank) }\end{array}$ & 11.2 & 85287 & 8188 \\
\hline Replace the existing coarse bubble diffusers & 3.8 & 29233 & 2806 \\
\hline Install photovoltaic panels & \multicolumn{3}{|c|}{ Not determined } \\
\hline
\end{tabular}

As a result of this audit process, very auspicious energy-saving measures were identified in both WWTPs, which allow substantial energy savings, namely $13 \%$ and $22 \%$ of the total energy consumption of WWTP1 and WWTP2, respectively. It also should be mentioned that the first two measures suggested for WWTP2 have already been 
implemented and that the values presented were confirmed by a second monitoring process. Fig. 3 shows the implementation of one of these measures, namely changing the operating profile of the submersible mixers of the anoxic tank. Thus, is possible to see the point from which the operating profile was modified. From this monitoring it was concluded that with this change the annual energy consumption of each of the mixers decreases from $56439 \mathrm{kWh}$ to $13796 \mathrm{kWh}$, resulting in an overall annual saving (for the two mixers) of $85287 \mathrm{kWh}$ as shown in Table 2.

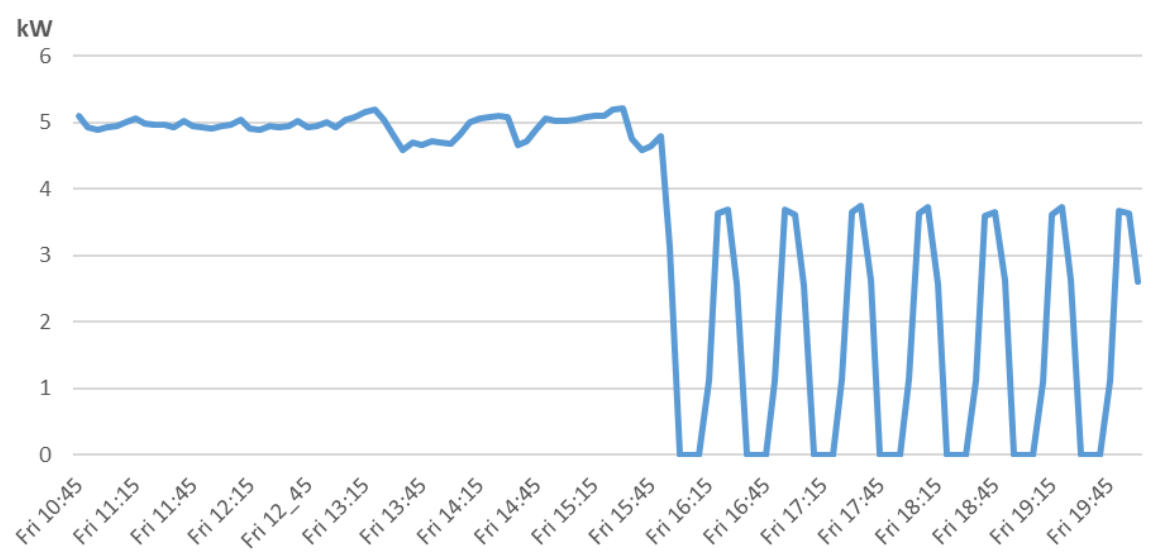

Fig. 3. Load diagram of one submersible mixer (anoxic tank).

One of the requirements considered in the definition of the energy-saving measures is the safeguard of the wastewater treatment process. Thus, the efficiency of the process was always under consideration and monitored to ensure the purpose of the WWTP, i.e., to treat wastewater and to comply with the values of the discharge license. Moreover, this was also confirmed by observing that the parameter values (TSS, BOD 5 and COD) at the end of the WWTP (in the return to the environment) and verifying that, like before the modifications, they continue to comply with the emission limit values stipulated in the WWTP's discharge license, as expressed in Table 3.

Table 3. Exit values and emission limit values for WWTP2.

\begin{tabular}{cc|c} 
& Exit Value & Emission Limit Value \\
\hline $\mathrm{TSS}(\mathrm{mg} / \mathrm{l})$ & 10 & 60 \\
$\mathrm{CBO}_{5}\left(\mathrm{mg} \mathrm{O}_{2} / \mathrm{l}\right)$ & 5 & 40 \\
$\mathrm{COD}\left(\mathrm{mg} \mathrm{O}_{2} / \mathrm{l}\right)$ & 25 & 150 \\
\hline
\end{tabular}

Five of the suggested energy-saving measures (changes in the operating profiles) prove to be quite important as they are relatively simple to implement, with no substantial associated costs, and allow some noteworthy energy and monetary savings without compromising the wastewater treatment process. These are the reasons for giving more emphasis to these five energy-saving measures in this study. Moreover, this type of 
measures was preferred for analysis as they can be easily identified and implemented by company members without the need for specialized companies.

\section{Conclusions}

From this study, it was possible to verify the role that aeration systems present in the wastewater treatment, accounting for the largest share of the energy consumption of the two WWTPs analyzed. This portion is not surprising since aeration plays an important role in the treatment process by providing the oxygen needed by the microorganisms to degrade the organic material. Nevertheless, it was also shown that other end uses such as submersible mixers, agitators or pumps may represent noteworthy portions of energy consumption as well.

As noted, the adoption of the energy-saving measures identified would significantly reduce the consumption of the two facilities, namely $13 \%$ and $22 \%$ for WWTP1 and WWTP2, respectively. In fact, from the implementation of simple measures, such as changing the operating profile of some equipment, it was possible to achieve significant energy savings in both facilities without compromising their function or the treatment process itself. It should be noted that the treatment process is safeguarded since the measures essentially propose the adjustment of the operation of the equipment to the current conditions of the WWTP. This safeguard was duly verified by the parameter values (TSS, $\mathrm{BOD}_{5}$ and $\mathrm{COD}$ ) that after the modifications, and as it was before, continue to satisfy the WWTP's discharge license. Thus, this work is a good example of the importance of the operational measures and how they should be the first step to be properly evaluated as they translate into substantial efficiency gains without requiring substantial investments.

Finally, the main contribution of this work is the statement that there are quite auspicious energy-saving measures, which can easily be identified by company members and are easy to implement while allowing substantial energy savings.

\section{Acknowledgments}

Bruno J. Cardoso acknowledges the financial support provided by the Portuguese Foundation for Science and Technology (FCT), under Doctoral grant PD/BD/142812/2018. This work has also been supported by FCT and European Regional Development Fund (FEDER) through COMPETE 2020 - Operational Program for Competitiveness and Internationalization (POCI), under the project Ren4EEnIEQ (PTDC/EMSENE/3238/2014 and POCI-01-0145-FEDER-016760 respectively). The authors would like to thank Águas do Norte, S.A. for providing the data used in this research, as well as to DTE, Lda. for the support provided. The research presented in this article was developed under the framework of the Energy for Sustainability Initiative of the University of Coimbra (UC) and the MIT Portugal Program. 


\section{References}

1. Copeland, C., Carter, N.T.: Energy-Water Nexus : The Water Sector's Energy Use. (2017)

2. Santana, M.V.E., Zhang, Q., Mihelcic, J.R.: Influence of water quality on the embodied energy of drinking water treatment. Environ. Sci. Technol. 48, 30843091 (2014). doi:10.1021/es404300y

3. IEA: Water Energy Nexus- Excerpt from the World Energy Outlook 2016. Int. Energy Agency. 60 (2016). doi:10.1021/es903811p

4. Wakeel, M., Chen, B., Hayat, T., Alsaedi, A., Ahmad, B.: Energy consumption for water use cycles in different countries: A review. Appl. Energy. 178, 868885 (2016). doi:10.1016/j.apenergy.2016.06.114

5. Hernández-Sancho, F., Molinos-Senante, M., Sala-Garrido, R.: Energy efficiency in Spanish wastewater treatment plants: A non-radial DEA approach. Sci. Total Environ. 409, 2693-2699 (2011). doi:10.1016/j.scitotenv.2011.04.018

6. Molinos-Senante, M., Sala-Garrido, R., Iftimi, A.: Energy intensity modeling for wastewater treatment technologies. Sci. Total Environ. 630, 1565-1572 (2018). doi:10.1016/j.scitotenv.2018.02.327

7. Gómez, T., Gémar, G., Molinos-Senante, M., Sala-Garrido, R., Caballero, R.: Assessing the efficiency of wastewater treatment plants: A double-bootstrap approach. J. Clean. Prod. 164, 315-324 (2017). doi:10.1016/j.jclepro.2017.06.198

8. Hernández-Chover, V., Bellver-Domingo, Á., Hernández-Sancho, F.: Efficiency of wastewater treatment facilities: The influence of scale economies. J. Environ. Manage. 228, 77-84 (2018). doi:10.1016/j.jenvman.2018.09.014

9. Silva, C., Rosa, M.J.: Energy performance indicators of wastewater treatment: A field study with 17 Portuguese plants. Water Sci. Technol. 72, 510-519 (2015). doi:10.2166/wst.2015.189

10. Longo, S., D’Antoni, B.M., Bongards, M., Chaparro, A., Cronrath, A., Fatone, F., Lema, J.M., Mauricio-Iglesias, M., Soares, A., Hospido, A.: Monitoring and diagnosis of energy consumption in wastewater treatment plants. A state of the art and proposals for improvement. Appl. Energy. 179, 1251-1268 (2016). doi:10.1016/J.APENERGY.2016.07.043

11. Di Fraia, S., Massarotti, N., Vanoli, L.: A novel energy assessment of urban wastewater treatment plants. Energy Convers. Manag. 163, 304-313 (2018). doi:10.1016/j.enconman.2018.02.058

12. Ministério da Economia e Inovação: Sistema de Gestão dos Consumos Intensivos de Energia (SGCIE). Diário da República, 1. ${ }^{a}$ série — N. ${ }^{\circ} 74-15$ de Abril de 2008

13. Lorenzo-Toja, Y., Vázquez-Rowe, I., Chenel, S., Marín-Navarro, D., Moreira, M.T., Feijoo, G.: Eco-efficiency analysis of Spanish WWTPs using the LCA+DEA method. Water Res. 68, 637-650 (2015). doi:10.1016/j.watres.2014.10.040

14. Gude, V.G.: Energy and water autarky of wastewater treatment and power 
generation systems. Renew. Sustain. Energy Rev. 45, 52-68 (2015). doi:10.1016/j.rser.2015.01.055

15. Mamais, D., Noutsopoulos, C., Dimopoulou, A., Stasinakis, A., Lekkas, T.D.: Wastewater treatment process impact on energy savings and greenhouse gas emissions. Water Sci. Technol. 71, 303-308 (2015). doi:10.2166/wst.2014.521

16. Water Environment Research Foundation: Energy production and efficiency research - the roadmap to net-zero energy. (2011)

17. Gu, Y., Li, Y., Li, X., Luo, P., Wang, H., Robinson, Z.P., Wang, X., Wu, J., Li, F.: The feasibility and challenges of energy self-sufficient wastewater treatment plants. Appl. Energy. 204, 1463-1475 (2017). doi:10.1016/j.apenergy.2017.02.069

18. U.S. Environmental Protection Agency: Evaluation of energy conservation measures for wastewater treatment facilities. (2010) 